\title{
LA COBERTURA DE LOS ACCIDENTES DEL TRABAJO CON MOTIVO DEL DESEMPEÑO DE ACTIVIDADES SINDICALES. ENTRE UNA ADECUADA GARANTÍA Y UNA RESTRICCIÓN INJUSTIFICADA A LA LIBERTAD SINDICAL
}

\section{EMPLOYMENT ACCIDENTS COVERAGE AND THE EXECUTION OF UNION ACTIVITIES \\ BETWEEN AN ADEQUATE GUARANTEE AND AN UNJUSTIFIED RESTRICTION TO THE FREEDOM OF ASSOCIATION}

\author{
PEDRO CONTADOR ABRAHAM * \\ LEONARDO HOLGADO VARGAS **
}

\begin{abstract}
"El sistema de gobierno más perfecto es aquel que produce mayor suma de felicidad posible, mayor suma de seguridad social y mayor suma de estabilidad politica"
\end{abstract}

(Simón Bolívar, Discurso de Angostura, 15 de febrero de 1819) ${ }^{1}$

\begin{abstract}
RESUMEN: La presente investigación pretende efectuar un análisis crítico de la cobertura, que la seguridad social chilena efectúa a los trabajadores que ejercitan su derecho a la Libertad Sindical, particularmente en períodos de huelga, teniendo a la vista su efecto suspensivo en la relación laboral contemplado en el artículo 377 del Código del Trabajo, para lo cual se procede a la revisión de la jurisprudencia administrativa sobre el inciso tercero del artículo $5^{\circ}$ de la ley $\mathrm{N}^{\circ} 16.744$, que otorga cobertura por los accidentes laborales que sufran los dirigentes sindicales en el ejercicio de su función de representación. Sin embargo, a partir de esta consagración normativa, se ha entendido hasta ahora, que no corresponde otorgar igual protección a trabajadores socios o afiliados a un sindicato, cuando éstos participan en una actividad sindical, especialmente durante una huelga. Para efectuar el análisis y conclusiones, se han considerado los Convenios de la OIT sobre Libertad Sindical, los pronunciamientos del Comité de Libertad Sindical, así como la legislación comparada existente en la materia en algunos países de Iberoamérica.
\end{abstract}

PALABRAS CLAVE: Dirigente sindical, trabajador sindicalizado, libertad sindical, buelga, cobertura de la seguridad social, accidentes del trabajo.

ABSTRACT: The following research intends to bring about a critical analysis on the range of coverage provided by the chilean social security system, to protect those workers who practice their right to Freedom of Association. This analysis is focused particularly during strikes, and regards the suspensive effect related to the labor relation which is considered in the Labor Code, article 337. A revision of the administrative jurisprudence has been carried

*Abogado, Licenciado en Ciencias Jurídicas y Sociales, Universidad de Concepción. Magíster @ en Derecho del Trabajo y de la Seguridad Social, Universidad de Talca - Universidad de Valencia. Profesor de Derecho del Trabajo y Seguridad Social en las Universidades de Talca y San Sebastián. Correo electrónico; pcontadorabraham@gmail.com.

**Abogado, Licenciado en Ciencias Jurídicas y Sociales, Universidad Central. Magíster (C) en Derecho del Trabajo y de la Seguridad Social, Universidad de Talca - Universidad de Valencia. Abogado asesor de la Federación Metropolitana de Funcionarios de Salud Municipal (FREMESAM). Profesor de Derecho Laboral y Fundamentos Filosóficos del Derecho, FCJS de la Universidad Central. Correo electrónico; leholgado@gmail.com

${ }^{1}$ Bolívar, disponible en http://www.ensayistas.org/antologia/XIXA/bolivar/bolivar2.htm. 
Pedro Contador Abraham Y Leonardo Holgado Vargas / La cobertura de los accidentes del Trabajo con motivo del desempeño de actividades sindicales. Entre una adecuada garantía y una restricción injustificada a la libertad sindical. out, especially article 5 paragraph 3 pertaining law $\mathrm{N}^{\mathrm{o}} 16.744$, which grants coverage to those employment accidents that union leaders might suffer when doing their representation duty. From this normative sanction, it has been understood so far that no equal protection should be granted to unionized workers or members when they participate in a union movement, especially during a strike. To achieve the analysis and conclusions, the ILO Freedom of Association Convention has been considered, the pronouncing of the Committee on Freedom of Association, and also the existing compared legislation regarding the topic in some spanish-american countries.

Key words: Union leader, unionized worker, freedom of association, strike, social security coverage, employment accidents.

\section{INTRODUCCIÓN}

En la presente investigación se abordará la cobertura del sistema de seguridad social chileno de los accidentes producidos en el desarrollo de actividades propias del ejercicio de la Libertad Sindical.

Para ello se expondrán los siguientes elementos: en primer lugar se revisarán los aspectos conceptuales relacionados con la Libertad Sindical como derecho fundamental, especialmente en lo que se refiere a la huelga, para seguir con algunas referencias normativas a la protección de los sistemas de seguridad social respecto de los trabajadores en huelga, haciendo especial mención al sistema de aseguramiento de los accidentes del trabajo vigente en Chile, para continuar con el análisis de la jurisprudencia de la Superintendencia de Seguridad Social sobre casos concretos sometidos a su dictamen y una breve comparación del sistema jurídico iberoamericano en materia de riesgos del trabajo, concluyendo con un análisis crítico de los principales aspectos tratados.

Frecuentemente en el despliegue de la investigación se hará especial referencia al ejercicio de la huelga como derecho fundamental y a la incoherencia que la normativa nacional tiene con ese instituto esencial del derecho colectivo del trabajo, normativa que, de acuerdo a la doctrina "trasunta una evidente y mal disimulada agresividad con la tutela directa de los trabajadores", 2 más aún, se le ha calificado como una legislación transgresora de la Libertad Sindical, ${ }^{3}$ pues en el propio ordenamiento laboral, la huelga se encuentra permitida sólo como una fase residual y en extremo acotada de un proceso de negociación colectiva excesivamente reglamentado, y que tiene como límite general la exclusión de una eventual alteración del equilibrio del poder en la empresa en favor de los trabajadores.

\section{DERECHOS Y PRINCIPIOS FUNDAMENTALES EN PUGNA. ASPECTOS CONCEPTUALES.}

La Libertad Sindical en nuestra doctrina ha sido definida como el "derecho de los trabajadoresy sus agrupaciones para organizarse y defender sus intereses comunes", ${ }^{4}$ y calificada por la doctrina y por el Comité de Libertad Sindical como un derecho humano fundamental o esencial, ${ }^{5}$ que se manifiesta en tres institutos básicos como son: a) la Organización Sindical, ya sea el Sindicato para los trabajadores sujetos al Código del Trabajo o la Asociación de Funcionarios en el

\footnotetext{
2 Caamaño y Ugarte (2008) p. 80

${ }^{3}$ Gamonal (2011) p. 54.

${ }^{4}$ Ibídem p.59.

5 Tapia (2007) pp. 174-176.
} 
Pedro Contador Abraham Y Leonardo Holgado Vargas / La cobertura de los accidentes del Trabajo con motivo del desempeño de actividades sindicales. Entre una adecuada garantía y una restricción injustificada a la libertad sindical. ámbito de la Administración Pública, en el caso de nuestro ordenamiento jurídico laboral; b) la Negociación Colectiva, permitida en el nivel de la empresa para los trabajadores sometidos al código laboral y prohibida expresamente, por ejemplo, por el artículo $4^{\circ}$ inciso $2^{\circ}$ de la ley $\mathrm{N}^{\circ}$ 19.378 en el sector de Salud Primaria Municipalizada y c) la Huelga, que por su parte se encuentra permitida excepcionalmente para los trabajadores contratados por el Código del Trabajo, que participen de un procedimiento reglado de negociación colectiva y, prohibido explícitamente en el artículo $19 \mathrm{~N}^{\circ} 16$ inciso $6^{\circ}$ de nuestra Constitución para el sector público y empresas o corporaciones que presten servicios esenciales.

Por otra parte, la doctrina manifiesta que existen expresiones individuales y colectivas de la Libertad Sindical. En la primera, correspondería al derecho de los trabajadores, considerados como personas naturales, de participar o no en la creación de un sindicato o de pertenecer o no a uno de ellos, y -en el modelo normativo chileno aún vigente-, de involucrarse o no en un proceso de negociación colectiva. La expresión colectiva, en tanto, se manifiesta en la defensa de los intereses colectivos de los trabajadores. ${ }^{6}$

Como acertadamente indica el profesor Ermida, la Libertad Sindical individual incluye el derecho a desarrollar actividad sindical, siendo ésta el objeto de este derecho fundamental, la que incluso puede realizarse sin que exista propiamente tal una organización sindical. ${ }^{7} \mathrm{La}$ actividad sindical, por tanto, puede ser definida, como todas aquellas acciones tendientes a la defensa y promoción de los intereses colectivos de los trabajadores, incluyendo la negociación colectiva y el derecho a huelga. ${ }^{8}$

En virtud de lo dispuesto en los Convenios $\mathrm{N}^{\circ} \mathrm{s} 87$ y 98 de la Organización Internacional del Trabajo (OIT), ratificados y vigentes en nuestro país, los cuales se entienden pertenecer al bloque de constitucionalidad, ${ }^{9}$ por así expresarlo el inciso $2^{\circ}$ del artículo $5^{\circ}$ de la Carta Política de nuestra República, deben ser considerados en la categoría de derechos humanos fundamentales, o sea, deben ser entendidos como un límite a la soberanía estatal y, en el caso de las relaciones de trabajo, también un límite al poder de dirección empresarial ${ }^{10}$ instaurado, por ejemplo, en el inciso $2^{\circ}$ del artículo 306 del Código Laboral- por expresa indicación del artículo $5^{\circ}$ del mismo código político, protegido por la tutela judicial efectiva que instaura el procedimiento por vulneración de derechos fundamentales de los artículos 485 y siguientes del Código del Trabajo. Igualmente, la doctrina enseña que existe una interdependencia entre la Libertad Sindical y los demás derechos fundamentales, a tal punto que los derechos individuales dependen de la Libertad Sindical. ${ }^{11}$

En este mismo sentido, el Convenio $\mathrm{N}^{\circ} 135$ de la OIT, también ratificado por Chile,

\footnotetext{
${ }^{6}$ Lanata (2012) p. 10.

${ }^{7}$ Ermida (2012 a) p. 32.

${ }^{8}$ Caamaño y Ugarte (2008) p. 15.

9 Dicho planteamiento supone la integración de todos los principios y normas sobre derechos humanos, cualquiera que sea su fuente, en un bloque de la más alta jerarquía y fuerza normativa, tanto en el orden interno, como en el internacional. En Barbagelata (2009) pp. 221-222.

${ }^{10}$ Como anota Salinero "el Plan Laboral, a través de la Negociación Colectiva, instituyó la subordinación del trabajo al capital y contribuyó a garantizar la tasa de ganancia libre de interferencias laborales reforzando el patrón de acumulación derivado del modelo económico adoptado y para lo cual estableció un conjunto de disposiciones protectoras a la actividad económica de la empresa", en Salinero (2006) p. 35.

${ }^{11}$ Ermida (2012 a) p. 25.
} 

establece una protección especial para los representantes de los trabajadores en el ejercicio de la Libertad Sindical, para no ser discriminados arbitrariamente ni interferidos en sus actividades gremiales. Los principios hasta aquí resumidos, también son aplicables a las relaciones de trabajo del sector público por medio del Convenio $\mathrm{N}^{\circ} 151$ de la propia OIT.

Lo anteriormente expuesto no significa que las dimensiones integrantes de la Libertad Sindical, que al decir de un autor nacional "no es divisible, pues los institutos sobre que se aplica sindicato, negociación colectiva y buelga- tienen su fundamento en el efectivo ejercicio del otro", ${ }^{12}$ sean absolutas, prueba de ello son las importantes limitaciones existentes para cada uno de sus componentes, así como en el caso de colisión con otros derechos fundamentales involucrados, ${ }^{13}$ en situaciones fácticas o jurídicas concretas, en que las autoridades legislativas y/o judiciales se ven en la obligación de ponderarlos para determinar la proporcionalidad de tales limitaciones, siempre que no vulneren el contenido esencial de los derechos fundamentales en pugna. ${ }^{14}$

El caso de la huelga es especialmente relevante en el marco de esta investigación, porque como veremos un poco más adelante, además de las restricciones normativas a este derecho fundamental existentes en nuestro ordenamiento constitucional y laboral, subsisten otras que la doctrina laboralista frecuentemente denomina accesorias, como las que podemos encontrar en el campo de la seguridad social, las que se fundarían en el denominado Principio de No Interferencia o Neutralidad del Estado frente al conflicto colectivo, ${ }^{15}$ acuñado por la doctrina y jurisprudencia constitucional española, mediante el cual la posición del trabajador en huelga, en relación a la Seguridad Social, se configura como una situación de asimilación de alta, a efectos de permitir la generación de los derechos ligados a tal exigencia, prohibiéndose sin embargo, la atribución de prestaciones de incapacidad laboral transitoria y de desempleo, vale decir, no deben existir ausencias de cotizaciones por el ejercicio del derecho de huelga que corran a cargo del Estado y no debe sufragar éste las negativas consecuencias que conllevan dichas ausencias. Sin embargo, esta limitación está acotada a las antedichas prestaciones de la seguridad social y su alcance será precisado más adelante.

\section{ANÁLISIS DE LA REGULACIÓN NACIONAL RELATIVA A LA HUELGA.}

Se ha señalado por la doctrina, que la huelga tiene una naturaleza de autotutela laboral caracterizada por la suspensión o alteración del trabajo, unida a la voluntad de reclamo o protesta y su manifestación colectiva. ${ }^{16} \mathrm{~A}$ partir de estas características, se ha definido la huelga como la abstención colectiva del trabajo, ${ }^{17}$ o la perturbación del proceso productivo del empleador para el que se presta el trabajo, a través de la realización de diversos comportamientos posibles y, principalmente, mediante la abstención o cesación del trabajo, decididos de forma concertada y ejercidos colectivamente por los trabajadores en defensa de

\footnotetext{
12 Tapia (2009) p. 151.

13 Gamonal (2011) p. 66.

14 Ugarte (2011) pp. 67-73.

15 Como se señala en Monereo (2002), y en sentencias del Tribunal Constitucional (STC), 13/1984, de 3 de febrero de 1984 y 48/1991, de 28 de febrero de 1991, disponible en http://hj.tribunalconstitucional.es/HJ/elGR/Resolucion/Show/SENTENCIA/1991/48

${ }^{16}$ Ermida (2012 b) pp. 11-37.

${ }^{17}$ Gamonal (2011) p. 369.
} 

sus intereses. ${ }^{18}$

desempeño de actividades sindicales. Entre una adecuada garantía y una restricción injustificada a la libertad sindical.

A partir de los pronunciamientos del Comité de Libertad Sindical, ${ }^{19}$ la doctrina nacional ${ }^{20}$ y comparada, ${ }^{21}$ han indicado que el efecto principal de la huelga en las relaciones individuales de trabajo, implica la suspensión del contrato de trabajo, afirmándose, sin embargo, que ello no conlleva su terminación y, por el contrario, se mantiene la antigüedad laboral aunque no se generen remuneraciones.

En un contexto de plena Libertad Sindical, el profesor Ermida sostiene que la huelga es trivalente pues puede llegar a ser un medio de acción sindical, un conflicto colectivo de trabajo y una forma de solucionar el conflicto o todos ellos a la vez. ${ }^{22}{ }^{23}$ Como contraposición, la huelga en Chile es concebida como una etapa o trámite del procedimiento de negociación colectiva reglada, que tiene lugar después que las partes hayan efectuado una negociación directa, y vinculada exclusivamente a la negociación o renegociación de un contrato colectivo, privando al derecho de huelga de toda otra finalidad. ${ }^{24}$

En este contexto restrictivo, se inscribe a nuestro juicio el artículo 377 del Código del Trabajo, ${ }^{25}$ sobre el cual nuestra doctrina ha señalado, en lo atingente al objeto de este estudio; que durante la huelga los efectos del contrato de trabajo se suspenden, aunque las partes siguen ligadas jurídicamente y que la suspensión opera por disposición expresa de la ley, afectando sólo a los trabajadores que se encuentran en huelga. ${ }^{26}$ Así, el trabajador a su iniciativa, deja de concurrir a sus labores, sin que el empleador pueda poner término al contrato u obligarlo a cumplir con él, pues no implica un incumplimiento contractual. ${ }^{27}$ Por su parte, el empleador queda liberado de su obligación de remunerar el trabajo convenido y de proporcionar ese trabajo. ${ }^{28}$ También se ha señalado que no obstante esta suspensión del contrato, persiste entre las partes el deber de buena fe contractual y en ciertos casos y un contexto de conflictividad de la huelga que debe ser ponderado, el empleador retendría su poder disciplinario. ${ }^{29}$

\footnotetext{
18 Palomeque y Alvarez de La Rosa (2013) p. 445.

${ }^{19}$ Se ha resuelto que la deducción salarial de los días de huelga no plantea objeciones desde el punto de vista de los principios de libertad sindical. ORGANIZACIÓN INTERNACIONAL DEL TRABAJO (2006) p. 140.

${ }^{20}$ Por ejemplo, ya en el año 1957 el autor nacional Humeres (1957) p. 87, expresaba: "en la época actual, en que la buelga se considera como derecho, todos están de acuerdo en que no rompe el contrato y solamente suspende su cumplimiento.".

${ }^{21}$ Ermida (2012 b) p.48.

22 Ibídem, pp. 14-15.

23 Asimismo, la doctrina comparada sostiene que la huelga puede, tener entre otras motivaciones: a) huelga política; b) huelga de solidaridad; c) huelga por conflictos jurídicos y d) huelga novatoria. En Sala Franco (2011) pp.1253-1254.

${ }^{24}$ Caamaño y Ugarte (2008) pp. 81-82.

25 "Durante la buelga o el cierre temporal o lock-out se entenderá suspendido el contrato de trabajo, respecto de los trabajadores y del empleador que se encuentren involucrados o a quienes afecte, en su caso. En consecuencia, los trabajadores no estarán obligados a prestar sus servicios ni el empleador al pago de sus remuneraciones, beneficios y regalías derivadas de dicho contrato.

Durante la buelga o durante el cierre temporal o lock-out, los trabajadores podrán efectuar trabajos temporales, fuera de la empresa, sin que ello signifique el término del contrato de trabajo con el empleador.

Durante la buelga los trabajadores podrán efectuar voluntariamente las cotizaciones previsionales o de seguridad social en los organismos respectivos. Sin embargo, en caso de lock-out, el empleador deberá efectuarlas respecto de aquellos trabajadores afectados por éste que no se encuentren en buelga.".

26 Thayer y Novoa (2012) p.100.

27 Gamonal (2011) p. 395.

${ }^{28}$ Lanata (2012) pp. 225-226.

${ }^{29}$ Sala Franco pp.1282-1285.
} 
Respecto al pago de las cotizaciones previsionales durante el período de huelga, dado que con las reformas generadas en nuestro sistema de seguridad social, a partir del año 1981, la generalidad de las imposiciones son de cargo del trabajador, con excepción, entre otras, de las cotizaciones para el seguro de la ley $\mathrm{N}^{\circ} 16.744,{ }^{30}$ las cotizaciones que le corresponden al empleador en el Seguro de Desempleo ${ }^{31}$ y en trabajos pesados, ${ }^{32}$ así como el financiamiento del Seguro de Invalidez y Sobrevivencia. ${ }^{33}$ Por ello, el artículo 377 hace recaer en los propios trabajadores el pago de tales cotizaciones durante los periodos de huelga, con la salvedad que, dichos pagos tienen el carácter de voluntarios para los trabajadores. ${ }^{34}$

Cabe hacer presente que el proyecto de ley que moderniza el sistema de relaciones laborales, introduciendo modificaciones al Código del Trabajo, boletín 9835-13, mantiene inalterables las disposiciones del actual artículo $377 .{ }^{35}$

\section{COBERTURA DE LA SEGURIDAD SOCIAL A LOS TRABAJADORES EN HUELGA}

Cabe destacar que en los distintos regímenes de seguridad social chileno, no se contienen normas específicas sobre la situación del trabajador en huelga y su acceso a las prestaciones durante estos periodos, razón por la cual, si el trabajador opta por no cotizar durante la huelga, deberá verse caso a caso su situación previsional, según la contingencia que pudiera afectarle durante tales períodos, para determinar si tendrá acceso a prestaciones o, por el contrario, perderá o verá disminuidos sus beneficios de la seguridad social. ${ }^{36}$

Así por ejemplo, relacionando los artículos 54 letra b) y 59 letra d) del D.L. $\mathrm{N}^{\circ} 3500$, de 1980, se puede concluir que las A.F.P. serán responsables de enterar en la cuenta de capitalización individual, el aporte adicional, ${ }^{37}$ destinado a financiar la pensión de sobrevivencia de los afiliados no pensionados que fallezcan (entre otras hipótesis que contempla la norma), cuando precisamente el afiliado trabajador dependiente, hubiere dejado de prestar servicios por

\footnotetext{
30 Artículo 15 letras a) y b) ley $\mathrm{N}^{\circ} 16.744$.

31 Artículo 5 letra b) ley $\mathrm{N}^{\circ} 19.728$.

32 Artículo 17 bis D.L. N 3.500.

33 Artículo 16 inciso cuarto del D.L. N 3.500.

${ }^{34}$ Lanata (2012) pp. 225-226.

35 "Artículo 357.- Suspensión del contrato de trabajo y efectos de la buelga y el lock-out. Durante la buelga o lock-out se entenderá suspendido el contrato de trabajo respecto de los trabajadores y del empleador que se encuentren involucrados o a quienes afecte, en su caso. En consecuencia, los trabajadores no estarán obligados a prestar sus servicios ni el empleador al pago de sus remuneraciones, beneficios y regalias derivadas de dicho contrato.

En el caso del inciso anterior, los trabajadores podrán efectuar trabajos temporales, fuera de la empresa, sin que ello signifique el término del contrato de trabajo con el empleador.

Durante la buelga, los trabajadores involucrados en la negociación podrán pagar voluntariamente sus cotizaciones previsionales o de seguridad social en los organismos respectivos. Sin embargo, en caso de lock-out el empleador deberá efectuarlas respecto de aquellos trabajadores afectados por este que no se encuentren en huelga.”. En boletín de indicaciones de 14.09.2015, Segundo Trámite Constitucional, Senado de la República. Disponible en http://www.senado.cl/appsenado/templates/tramitacion/index.php.

${ }^{36}$ En similar sentido, Rojas (2014) p. 376.

37 Artículo 53 inciso primero del D.L. N 3.500: "Se entenderá por aporte adicional el monto, expresado en Unidades de Fomento, que resulte de la diferencia entre el capital necesario para financiar las pensiones de referencia más la cuota mortuoria y la suma del capital acumulado por el afiliado y el Bono de Reconocimiento, a la fecha en que el afiliado fallezca o quede ejecutoriado el dictamen que declara definitiva la invalidez. Cuando dicha diferencia sea negativa, el aporte adicional será igual a cero.".
} 
Pedro Contador Abraham Y Leonardo Holgado Vargas / La cobertura de los accidentes del Trabajo con motivo del desempeño de actividades sindicales. Entre una adecuada garantía y una restricción injustificada a la libertad sindical. término o suspensión del contrato (v. gr. durante una huelga), siempre que el fallecimiento se hubiere producido dentro de los doce meses siguientes del término o suspensión del contrato, debiendo registrar un mínimo de seis meses de cotizaciones el año anterior al último día del mes en que hayan dejado de prestar servicios, o éstos se hayan suspendidos. Para garantizar el pago de estas obligaciones, las AFP deberán contratar el denominado Seguro de Invalidez y Sobrevivencia.

Respecto del Seguro de Cesantía, en el evento de no existir pago de cotizaciones para este Seguro durante el periodo de huelga y ello importe, eventualmente, que el trabajador no pueda acceder al pago de las prestaciones por cesantía, ${ }^{38}$ por no reunir el número mínimo de cotizaciones a que se refieren los artículos 12 y 24 de la ley $\mathrm{N}^{\circ} 19.728$, el trabajador no podría ejercer la acción resarcitoria a que se refiere el artículo 17 de la citada ley, ${ }^{39}$ toda vez que en virtud del artículo 377 del Código del Trabajo, durante la huelga se suspende el contrato de trabajo y en consecuencia, cesa la obligación del empleador de efectuar cotizaciones para el Seguro de Cesantía, razón por la cual no existiría tampoco en estos casos un "incumplimiento" del empleador de su obligación de enterar cotizaciones, que justifique la acción indemnizatoria del aludido artículo 17.

Respecto al otorgamiento de licencias médicas en los períodos de huelga, la jurisprudencia de la Superintendencia de Seguridad Social, ${ }^{40}$ ha resuelto que conforme a la definición contenida en el artículo $1^{\circ}$ del D.S. N 3 , de 1984, del Ministerio de Salud, la licencia médica tiene entre sus finalidades que el trabajador falte en forma justificada a su trabajo o reduzca su jornada, en su caso, y que perciba un subsidio o mantenga su remuneración, mientras se encuentra afectado de dicha incapacidad laboral temporal. En razón de lo anterior, la mencionada Superintendencia ha dictaminado que durante la huelga, procede que se autoricen licencias médicas cuando éstas sean la continuación de otras, de las que ha venido haciendo uso el trabajador desde antes del inicio de la huelga. Por el contrario, las licencias médicas de los trabajadores involucrados, iniciadas durante la huelga, deben rechazarse, salvo por los días de reposo posteriores al término de ella.

La Superintendencia de Seguridad Social ha dictaminado igualmente, que durante la huelga los trabajadores podrán efectuar voluntariamente las cotizaciones previsionales, por lo tanto, si en el ejercicio de esa facultad el trabajador ha enterado las respectivas cotizaciones, tendrá derecho a las prestaciones de seguridad social, y entre ellas, al subsidio por incapacidad laboral de la misma manera que si hubiera estado trabajando durante el período de la huelga.

Respecto del pago del subsidio por incapacidad laboral que generen las licencias médicas que se pueden autorizar durante los períodos de huelga, la Superintendencia de Seguridad Social ha señalado que conforme lo dispone el inciso primero de los artículos $4^{\circ}$ y $8^{\circ}$ del

\footnotetext{
${ }^{38}$ La cesantía como podrá suponerse, solo puede verificarse en estos casos con posterioridad al término de la huelga y una vez reanudadas las labores suspendidas.

39 "Artículo 17.- Sin perjuicio de lo señalado en el inciso quinto del artículo 11, en el evento de no existir pago de cotizaciones, el trabajador tendrá derecho a exigir al empleador el pago de todas las prestaciones que tal incumplimiento le impidió percibir. El derecho anterior se entiende irrenunciable para todos los efectos y no se opondrá al ejercicio de las demás acciones que correspondan. La sentencia que establezca el pago de las prestaciones ordenará, además, a título de sanción, el pago de las cotizaciones que adeude el empleador con los reajustes e intereses que correspondan, de acuerdo al artículo 11, para que éstas sean enteradas en la Sociedad Administradora.".

${ }^{40}$ V. gr. Ordinarios Nº. 33878, de 2005; 53137, de 2009; 11198, de 2012 y 42403, de 2012.
} 
Pedro Contador Abraham Y Leonardo Holgado Vargas / La cobertura de los accidentes del Trabajo con motivo del desempeño de actividades sindicales. Entre una adecuada garantía y una restricción injustificada a la libertad sindical. D.F.L. $\mathrm{N}^{\circ}$ 44, de 1978, del Ministerio del Trabajo y Previsión Social, los subsidios por incapacidad laboral común se calculan de acuerdo al promedio de las remuneraciones netas, devengadas en los tres meses calendario más próximos al de inicio de la licencia y si un trabajador en uno o varios de los meses a considerar en el cálculo de estos beneficios no trabajó todo el mes, ni tampoco devengó subsidios por los días no trabajados, no es posible elegir otros meses en los cuales registre ingresos por el mes completo, por cuanto la norma legal aplicable hace referencia a "los tres meses calendario más próximos al mes en que se inicia la licencia”. Tampoco es posible, en la situación anterior, que para obtener el promedio de la remuneración mensual neta, se divida por el número de días efectivamente trabajados, lo que permite concluir que los tres meses son meses calendario, no pudiendo entenderse que se trata de 90 días de remuneraciones. De acuerdo con lo anterior, en la medida que se cuente con remuneraciones en los tres meses más próximos al inicio de la licencia, aun cuando se haya trabajado parcialmente por haber estado en huelga, deben ser consideradas las remuneraciones percibidas por el trabajador en dichos meses, dividiendo el monto de dicha remuneración por el número de días efectivamente trabajados y multiplicando el resultado por 30.

Finalmente, respecto del contrato de salud, entre un trabajador afiliado ejerciendo su derecho a huelga y una Institución de Salud Previsional, el inciso décimo del artículo 197 del D.F.L. $N^{\circ}$ 1, de 2006 del Ministerio de Salud que fija el texto refundido, coordinado y sistematizado del Decreto Ley $\mathrm{N}^{\circ} 2.763$, de 1979 y de las leyes $\mathrm{N}^{\circ} 18.933$ y $\mathrm{N}^{\circ} 18.469$, dispone que no se considerará incumplimiento del contrato por parte del afiliado, el hecho de no haberse enterado por su empleador o por la entidad pagadora de la pensión, en su caso, las cotizaciones de salud pactadas, y será obligación de la ISAPRE comunicar esta situación al afiliado dentro de los tres meses siguientes contados desde aquél en que no se haya pagado la cotización.

\section{COBERTURA DEL SEGURO DE ACCIDENTES DEL TRABAJO Y ENFERMEDADES EN LAS ACTIVIDADES SINDICALES}

Especial preocupación nos merece, dada su incidencia con el ejercicio del derecho a la Libertad Sindical, la cobertura de los accidentes del trabajo y enfermedades profesionales en actividades sindicales, con especial referencia a la huelga, a partir de lo indicado en el artículo $5^{\circ}$ de la ley $\mathrm{N}^{\circ} 16.744,{ }^{41}$ cuyo inciso tercero otorga cobertura por los accidentes laborales a los dirigentes sindicales por los accidentes laborales que sufran, a causa o con ocasión del desempeño de sus cometidos gremiales, sin distinguir entre el sector privado (sindicatos en sentido estricto) o sector público (rigurosamente denominadas asociaciones de funcionarios), pero que, a contrario sensu, desprotegería a los socios o afiliados de base de la organización sindical, por los siniestros laborales que puedan ocurrirles durante su actividad sindical.

41 "Para los efectos de esta ley se entiende por accidente del trabajo toda lesión que una persona sufra a causa o con ocasión del trabajo, y que le produzca incapacidad o muerte.

Son también accidentes del trabajo los ocurridos en el trayecto directo, de ida o regreso, entre la habitación y el lugar del trabajo, y aquéllos que ocurran en el trayecto directo entre dos lugares de trabajo, aunque correspondan a distintos empleadores. En este último caso, se considerará que el accidente dice relación con el trabajo al que se dirigía el trabajador al ocurrir el siniestro.

Se considerarán también accidentes del trabajo los sufridos por dirigentes de instituciones sindicales a causa o con ocasión del desempeño de sus cometidos gremiales.

Exceptuanse los accidentes debidos a fuerza mayor extraña que no tenga relación alguna con el trabajo y los producidos intencionalmente por la víctima. La prueba de las excepciones corresponderá al organismo administrador.". 
Además, debe tenerse en cuenta el artículo $9^{\circ}$ del Decreto Supremo $\mathrm{N}^{\circ}$ 101, de 1968 del Ministerio del Trabajo y Previsión Social, Reglamento para la aplicación de la ley $\mathrm{N}^{\circ} 16.744$, el cual establece el significado de "Las expresiones a causa o con ocasión del desempeño de sus cometidos gremiales, empleadas por el inciso $3^{\circ}$ del artículo $5^{\circ}$ de la ley, comprenden no sólo los accidentes ocurridos durante la faena y en el sitio en que ella o las actuaciones sindicales se realizaban, sino también los acaecidos antes o después, fuera de dichos lugares, pero directamente relacionados o motivados por las labores gremiales que el dirigente va a cumplir o ha cumplido.".

\section{6. $\quad$ ANÁLISIS JURISPRUDENCIAL DE LA COBERTURA DE LA LEY N 16.744 EN ACTIVIDADES SINDICALES}

A continuación, se ofrece una revisión general de los criterios de cobertura de la ley $\mathrm{N}^{\circ}$ 16.744, que la Superintendencia de Seguridad Social ha resuelto en materia de actividades sindicales:

a) Cobertura prestacional de los dirigentes sindicales

En el Ordinario $N^{\circ} 7.156$, de 1992, la Superintendencia resolvió no otorgar la cobertura al accidente sufrido por un dirigente sindical en un partido de fútbol realizado durante el paseo anual de su empresa, en cuya organización éste había colaborado. Para fundamentar el rechazo, se consideró que no existía nexo causal de orden laboral entre dicha actividad deportiva y su función sindical. En igual sentido, el Ordinario $N^{\circ}$ 44.504, de 2009 se reitera que el accidente sufrido por un dirigente sindical en un partido de fútbol organizado por el Sindicato no está cubierto por el Seguro de la ley $\mathrm{N}^{\circ} 16.744$, por la naturaleza recreativa de la actividad que originó el siniestro.

Por el contrario, en el Ordinario $\mathrm{N}^{\circ}$ 7.832, de 1996, habiéndose comprobado el acaecimiento de un accidente de trayecto, a la luz de los medios de prueba fidedignos que señala el artículo $7^{\circ}$ del Decreto Supremo N 101 de 1968, la Superintendencia de Seguridad Social resuelve otorgar cobertura a un dirigente sindical que se accidentó en un bus que llevaba víveres a trabajadores en huelga, desde la ciudad de Calama a la faena de la mina "El Abra". Por su parte, en el Ordinario $\mathrm{N}^{\circ} 11.401$, de 2002, también se otorgó cobertura de la ley $\mathrm{N}^{\circ}$ 16.744 a un dirigente sindical que sufrió un accidente descargando muebles para una actividad de capacitación de su sindicato.

El Ordinario $\mathrm{N}^{\circ}$ 47.999, de 2007, otorga cobertura de accidente laboral a un dirigente que tuvo un siniestro, producto de golpes recibidos de la Fuerza Pública en una manifestación de solidaridad con una huelga. Similar criterio que se expresa en el Ordinario $\mathrm{N}^{\circ} 36.058$, de 2008, en el cual la Superintendencia otorga cobertura a un dirigente sindical del área de educación municipal, accidentado producto de recibir de lleno el golpe de agua de un vehículo lanza aguas de Carabineros, en una marcha convocada por la Central Unitaria de Trabajadores.

Mediante Ordinario No 76.702 , de 2014, la Superintendencia de Seguridad Social resolvió que debe tenerse presente que el espíritu de la citada ley $\mathrm{N}^{0} 16.744$, es otorgar a los trabajadores una cobertura integral y suficiente por los riesgos que son propios de su actividad $\mathrm{y}$, respecto de los dirigentes de instituciones sindicales, debe entenderse que también tienen 
derecho a esa cobertura integral. Por lo tanto, es dable concluir que el acontecimiento -durante una reunión sindical desconocidos encapuchados, los cuales con fierros y palos, golpearon a los asistentes, y como consecuencia de este hecho, resultó un dirigente sindical con diversas lesiones,- tuvo su génesis en una causa de origen sindical, ya que no se acreditó de manera fehaciente, clara y precisa que el accidente haya tenido un origen diverso.

Otro criterio destacado de la jurisprudencia administrativa de la Superintendencia de Seguridad Social, se observa en el Ordinario $\mathrm{N}^{\circ} 23.154$, de 2002, en que se otorga cobertura de la ley $\mathrm{N}^{\circ} 16.744$ a un dirigente de una Asociación de Funcionarios, fallecido en una actividad recreativa del Servicio (Corporación de Asistencia Judicial del Biobío), a pesar que el organismo administrador había sostenido lo contrario, indicando que "sólo babría estado protegido por la ley $N^{\circ} 16.744$, durante el período que desarrolló y agotó las gestiones frente a su empleadora para finiquitar y acordar la organización del paseo de fin de año". Lo mismo ocurre en los Ordinarios $\mathrm{N}^{\circ}$ 45.061, de 2007 y el $\mathrm{N}^{\circ}$ 5.545, de 2010, en los que se otorga cobertura de accidente laboral a los siniestros acaecidos a dirigentes de Asociaciones de Funcionarios en sus horas libres si se demuestra convenientemente el nexo de causalidad. ${ }^{42}$.

Por último, es relevante señalar que el Ordinario $\mathrm{N}^{\circ}$ 47.026, de 2008, extiende la cobertura del artículo $5^{\circ}$ inciso $3^{\circ}$ de la ley $\mathrm{N}^{\circ} 16.744$ a los delegados del personal, por lo que se observa un adecuado concepto de la representación de trabajadores, en el sentido que se les protege en el mencionado Convenio $\mathrm{N}^{\circ} 135$ de la OIT.

Mediante Ordinario No 39.432, de 2015, la Superintendencia resolvió que la ley $\mathrm{N}^{\circ} 16.744$, al mencionar expresamente los accidentes del trabajo sufridos por dirigentes de instituciones sindicales, a causa o con ocasión del desempeño de sus cometidos gremiales, deja fuera a las enfermedades que éstos pudieran contraer en las mismas circunstancias y, por lo mismo, impide calificarlas como de naturaleza profesional, pues la ley no contempla tal situación.

Como puede apreciarse, en estos casos la jurisprudencia administrativa ha dado una extensión amplia a la cobertura de los accidentes del trabajo que sufran los dirigentes sindicales, cualesquiera que sean las actividades sindicales que realicen y sea que éstas desarrollen o no durante una huelga, bastando que se acredite el nexo causal directo o indirecto entre la lesión sufrida por el dirigente sindical y la acción sindical que éste desarrolla.

b) Cobertura prestacional de los demás trabajadores sindicalizados

La Superintendencia de Seguridad Social ha mantenido invariable su criterio, a través del cual establece que los trabajadores asociados a un sindicato, pero que no cumplen funciones como dirigente sindical, y sufren de un accidente con motivo de la asistencia a una actividad organizada por el sindicato, no correspondería que estos siniestros sean calificados como un accidente del trabajo. (Ordinario $\mathrm{N}^{\circ}$ 83.755, de 2014).

Tampoco tiene cobertura el accidente que le ocurra a los trabajadores como consecuencia de una "buelga ilegal", como la denomina el Ordinario $\mathrm{N}^{\circ} 30.036$, de 2011, ni están cubiertos por el Seguro contra accidentes laborales, los trabajadores en huelga que presten labores

\footnotetext{
${ }^{42}$ El oficio mencionado fundó el Dictamen $N^{\circ} 22.519$ de 2008 de la Contraloría General de la República que
} establece similar criterio. 
Pedro Contador Abraham Y Leonardo Holgado Vargas / La cobertura de los accidentes del Trabajo con motivo del desempeño de actividades sindicales. Entre una adecuada garantía y una restricción injustificada a la libertad sindical. temporales de las autorizadas en el propio artículo 377 del Código del Trabajo, que no se encuentren amparados por un contrato de trabajo, o bien, no sean trabajadores independientes que coticen para el Seguro de la ley N 16.744, (Ordinario N 19.144 de 2006).

Mediante Ordinario N 62.957, de 2013, la referida Superintendencia teniendo a la vista lo dispuesto en el artículo 377 del Código del Trabajo, resolvió que respecto de un trabajador que se encontraba corriendo en el recinto de la empresa, en el contexto de una "buelga legal", sintió un ruido en su rodilla derecha, cayendo de inmediato al piso sin poder pararse, no correspondía otorgar la cobertura de la ley $\mathrm{N}^{\circ} 16.744$, con la sola excepción contenida en el inciso tercero del artículo 5 de la ley $\mathrm{N}^{\circ} 16.744$, que se refiere a los accidente sufridos por los dirigentes de instituciones sindicales que se accidenten en cumplimiento de sus cometidos gremiales. En similar sentido, el Ordinario $\mathrm{N}^{\circ} 36.549$, de 2014, determinó que no procedía otorgar la cobertura del Seguro de la ley $\mathrm{N}^{\circ} 16.744$, al trabajador que se accidentó el día 1 de enero, a las 02:45 horas, al caer de la motocicleta en que se desplazaba desde su habitación en dirección al campamento donde trabajaba, para participar de una movilización junto a otros compañeros de labores, dentro del marco de una huelga.

A través del Ordinario $\mathrm{N}^{\circ}$ 38.233, de 2005, la Superintendencia de Seguridad Social resuelve otorgar cobertura a un trabajador que sufre un accidente de trayecto, al asistir a una reunión sindical que se desarrollaba en el lugar de trabajo y durante el horario laboral, no habiendo marcado su ingreso a las labores en el reloj control de la empresa.

c) Situaciones en que los criterios de calificación del accidente parecen complejos

En el Ordinario $\mathrm{N}^{\circ}$ 5.493, de 1994, no se otorga cobertura a un trabajador que no siendo dirigente sindical, fue atropellado después de una asamblea sindical, donde se incluye una discutible reflexión de ese servicio fiscalizador: "la actividad sindical es de carácter voluntario, por lo que el trabajador no se encuentra obligado a pertenecer a un sindicato $y$, si de hecho se afilia, las obligaciones que emanan de tal vínculo no se relacionan con su trabajo.".

En el Ordinario $\mathrm{N}^{\circ} 10.951$, de 2009, se otorga cobertura como accidente con ocasión del trabajo, al siniestro que le ocurrió a un dirigente que, gozando de permiso sindical, acude a su empresa para retirar el bus que conduciría al día siguiente desde su domicilio.

Como lo expresa el Ordinario $\mathrm{N}^{\circ}$ 46.706, de 2008, las lesiones de trabajadores en huelga que sufren los trabajadores que fueron atropellados por otro trabajador que ingresaba en una camioneta a la empresa, no están cubiertas por la ley $\mathrm{N}^{\circ} 16.744$, salvo que fueran dirigentes sindicales, ni en el caso del trabajador que se corta con un cuchillo, preparando almuerzo para sus compañeros en el "piquete de huelga", por no ser dirigente sindical, (Ordinario $\mathrm{N}^{\circ} 46.706$ de 2008).

Se observa, en términos generales, que el efecto de no otorgar la cobertura de la ley $\mathrm{N}^{\circ}$ 16.744, en el caso de un siniestro que afecte a un trabajador en huelga o en otra actividad sindical, será que éste deberá recibir las prestaciones médicas y pecuniarias que correspondan de su sistema de salud común, esto es, de la ISAPRE o del FONASA. 


\section{ALGUNAS CONSIDERACIONES SOBRE EL CRITERIO JURISPRUDENCIAL QUE NIEGA LA COBERTURA DE LA LEY N 16.744 A TRABAJADORES SINDICALIZADOS EN HUELGA}

En concepto de esta investigación, los criterios aplicados por la autoridad administrativa para negar la cobertura de la ley $\mathrm{N}^{\circ} 16.744$, a trabajadores sindicalizados que no tienen la calidad de dirigentes sindicales y que sufren accidentes durante los periodos de huelga o en otra actividad sindical, resultan parcialmente erróneos, ya que el efecto suspensivo que la huelga tiene en la relación laboral, de conformidad con el artículo 377 del Código del Trabajo, siendo excepcional, debe aplicarse en sentido estricto, más aun si se trata de excluir o negar prestaciones de seguridad social, por lo que no resulta procedente calificar a priori como no laboral, cualquier siniestro que en tales condiciones pueda afectar a los trabajadores.

Efectivamente, una interpretación de esta naturaleza desconoce la exigencia básica del artículo 5 de la ley $\mathrm{N}^{\circ}$ 16.744, para calificar a un siniestro como accidente del trabajo, cual es que entre la lesión y el trabajo exista una relación de causalidad a lo menos mediata o indirecta.

En este sentido, la suspensión de los efectos del contrato de trabajo en virtud de una huelga, no es en caso alguno total o absoluta. Por el contrario, la relación laboral, como lo ha anotado nuestra doctrina y jurisprudencia administrativa, ${ }^{43}$ persisten para ciertos efectos, como la antigüedad para los fines de gratificaciones, feriado, indemnización por años de servicios. Por ello, como ya se estudió y no obstante la suspensión del contrato, de todas formas se genera ciertos beneficios de seguridad social en favor de los trabajadores. En consecuencia, en situaciones de huelga y siempre respecto de trabajadores que no tengan la calidad de dirigentes sindicales, lo prudente es analizar caso a caso, si se mantiene el vínculo causal entre el trabajo y el siniestro, para calificar el accidente como laboral o común.

Así y no obstante estar suspendida la prestación de los servicios convenidos, en la realidad cotidiana de una huelga, se pueden dar algunas situaciones que suponen la persistencia de la relación causal, al menos indirecta, entre el trabajo y la lesión. Podemos citar, a vía ejemplar, los accidentes que puedan producirse cuando el trabajador concurre a cobrar las remuneraciones parciales que tenga derecho a percibir, por los días efectivamente trabajados en el mes de iniciación de la huelga, o los siniestros que le puedan ocurrir, durante la realización de trámites administrativos que deba efectuar en la empresa, para reconocer cargas familiares, aclarar descuentos a sus remuneraciones, recibir información sobre sus solicitudes ante el servicio de bienestar o requerir certificados a su empleador u otros trámites de finalidad análoga. También puede considerarse que existiría una relación causal, respecto de los accidentes que puedan sufrir los trabajadores en huelga, con motivo de realizar maniobras de rescate de sus compañeros de trabajo no involucrados en la huelga, o de bienes de la empresa, durante un incendio u otra contingencia análoga.

Asimismo, aun cuando resulta más discutible que los ejemplos de causalidad indicados anteriormente, puede plantearse si en los casos resueltos por la Superintendencia de Seguridad Social, y en que se ha negado la cobertura de la ley $\mathrm{N}^{\circ} 16.744$ al trabajador sindicalizado, se mantendría o no la relación causal, cuando el trabajador es atropellado mientras se dirigía hacia su casa habitación después de finalizada la asamblea sindical, respecto del cual el accidente no

${ }^{43}$ Gamonal (2011) p. 394. 
podría ser calificado de trayecto, por cuanto el desplazamiento no se inicia desde el lugar de trabajo como lo exige el inciso segundo artículo 5 de la ley $\mathrm{N}^{\circ} 16.744$, o respecto de aquellos trabajadores que sufren atropellos o lesiones con motivo de participar en piquetes de huelga fuera de la empresa, en donde la relación laboral está suspendida.

Recordemos nuevamente que la libertad sindical es un derecho fundamental, que incluye el derecho de los trabajadores de participar en actividades sindicales, incluyendo la huelga, facultad que de acuerdo a los Convenios 87 y $98^{44}$ de la OIT y el artículo 215 del Código del Trabajo, importa reconocer que los trabajadores deben gozar de adecuada protección contra todo acto de discriminación tendiente a menoscabar la libertad sindical en relación con su empleo, lo que incluye perjudicarlo en cualquier otra forma a causa de su afiliación sindical o de su participación en actividades sindicales.

Ahora bien, como podrá suponerse esta actividad discriminatoria del trabajador sindicalizado, ${ }^{45}$ no solo puede provenir del empleador, sino que del propio Estado, pues al decir del profesor Ermida ${ }^{46}$ puede existir una legislación que permita la huelga, pero que reglamente de una manera particularmente nociva para el trabajador, los efectos de esa huelga sobre su contrato individual de trabajo, introduciendo de esta manera una restricción total al derecho a huelga.

No divisamos, por tanto, las razones por las cuales respecto de trabajadores que se encuentran en similares situaciones fácticas y jurídicas frente a un sinestro, se pueda argumentar que sólo respecto de algunos de ellos (los que sufren un accidente con ocasión de su trabajo, pero no se encuentran en huelga) proceda otorgar cobertura de la ley $\mathrm{N}^{\circ} 16.744$, existiendo igualmente la relación causal exigida por la ley entre la lesión y el trabajo, respecto de los trabajadores que hayan legítimamente optado por ejercer su derecho a huelga y sufran un accidente causalmente relacionado con alguna circunstancia del contrato de trabajo cuyos efectos, como ya se dijo, persisten pese a la huelga.

\section{LA LEGISLACIÓN COMPARADA Y LA PROTECCIÓN CONTRA ACCIDENTES DEL TRABAJO EN EL EJERCICIO DE LA LIBERTAD SINDICAL ${ }^{47}$}

A nivel comparado existen pocas legislaciones en Iberoamérica como la chilena, que regulan expresamente los accidentes que sufren los dirigentes sindicales y/o trabajadores, con motivo del ejercicio de una actividad sindical. Solo para fines de ilustración destacaremos el caso de Colombia y de España, que como veremos otorgan una protección mucha más amplia

\footnotetext{
44 Artículo 1.1.- "Los trabajadores deberán gozar de adecuada protección contra todo acto de discriminación tendiente a menoscabar la libertad sindical en relación con su empleo.”.

45 Conforme al Comité de Libertad Sindical, la discriminación antisindical, representa una de las más graves violaciones de la libertad sindical. ORGANIZACIÓN INTERNACIONAL DEL TRABAJO (2006) p. 165.

${ }^{46}$ Ermida (2012 b) p.159.

47 Para consultar acerca de las contingencias cubiertas por los sistemas de riesgos del trabajo en Iberoamérica, se sugiere revisar el Banco de Información de los Sistemas de Seguridad Social Iberoamericanos, 2014. Disponible en www.oiss.org/bissi.
} 

que la chilena.

desempeño de actividades sindicales. Entre una adecuada garantía y una restricción injustificada a la libertad sindical.

a) En Colombia la Ley $N^{\circ} 1562$ de 2012, en artículo $3^{\circ}$ inciso cuarto señala:

"También se considerará como accidente de trabajo el ocurrido durante el ejercicio de la función sindical aunque el trabajador se encuentre en permiso sindical siempre que el accidente se produzca en cumplimiento de dicha función.”. ${ }^{48}$

b) El caso español:

En el ordenamiento jurídico español, las incapacidades temporales otorgan derecho a esta prestación en los siguientes casos: i) accidentes laborales, ii) enfermedades profesionales, iii) enfermedades comunes y iv) accidentes no laborales.

A su vez, el artículo 115 de la Ley General de Seguridad Social (LGSS) considera también como accidente de trabajo:

"b) Los que sufra el trabajador con ocasión o como consecuencia del desempeño de cargos electivos de carácter sindical, asi como los ocurridos al ir o al volver del lugar en que se ejerciten las funciones propias de dichos cargos.”.

Por otro lado, en la legislación española, la huelga produce como efecto "la suspensión contractual y sus consecuencias salariales (...) continuando vigente el contrato con suspensión del salario y derecho a reserva del puesto de trabajo para cuando la huelga finalice", 49 lo que se traduce en la "suspensión de la obligación de cotizar por parte del empresario y del propio trabajador, sin derecho a la prestación por desempleo ni a la económica por incapacidad temporal", no obstante lo cual el trabajador en estas situaciones "tendrá derecho a las prestaciones de asistencia sanitaria en una situación de incapacidad temporal", ${ }^{50}$ lo que se conoce doctrinariamente como Alta Especial, ${ }^{51}$ que se encuentra normada en los artículos 106.5 y 125.6 de la Ley General de Seguridad Social.

Existen, sin embargo, otras situaciones especiales en la legislación española que deben ser mencionadas para efectos de este estudio:

i. La huelga parcial de labores, en que los trabajadores "permanecerán en situación de alta ordinaria en la Seguridad Social durante toda la jornada, con independencia del número de horas trabajadas", o sea, se mantiene vigente para ambas partes de la relación laboral la obligación de cotizar en el sistema. $^{52}$

ii. La prestación económica por incapacidad temporal, se mantiene vigente igualmente:

\footnotetext{
48 Sobre esta disposición el Ministerio del Trabajo de Colombia ha señalado que la cobertura del sistema de riesgos del trabajo, comprende a todo aquel accidente que le suceda a un trabajador durante el ejercicio de actividad sindical. Oficio $\mathrm{N}^{\mathrm{O}}$ 1200000-190155, de 31.10.2014, disponible en http://www.fasecolda.com/files/2814/2530/5490/40.Min'Trabajo-Concepto-2014-N0190155 20141031.pdf.

${ }^{49}$ Sala Franco y Albiol (2003) p. 449.

${ }^{50}$ Ibídem, p. 456.

51 Aunque cesa la obligación de cotizar, continúa protegido por la seguridad social, con las restricciones ya reseñadas establecidas en la Ley de General de Seguridad Social. En Martín Valverde, Rodríguez -Sañudo y García (2013) p. 426.

52 Ibídem.
} 
Pedro Contador Abraham Y Leonardo Holgado Vargas / La cobertura de los accidentes del Trabajo con motivo del desempeño de actividades sindicales. Entre una adecuada garantía y una restricción injustificada a la libertad sindical.

a. "Cuando la contingencia de incapacidad temporal se hubiera producido antes de la buelga.".

b. "Cuando la duración de la buelga no alcance una jornada completa" porque subsisten las obligaciones del Alta Ordinaria.

c. $\quad$ En caso de pluriempleo, "no se perderá el derecho a subsidio por incapacidad temporal cuando la buelga solo se refiera a una de las empresas en que trabaja.".

d. Cuando exista la necesidad "de internamiento hospitalario y/ o intervención quirúrgica, tampoco se perderá el derecho al subsidio por incapacidad temporal.". 53

iii. El trabajador tendrá derecho a la prestación incapacidad temporal, aun encontrándose el trabajador en huelga, en caso de accidente de trabajo o enfermedad profesional. ${ }^{54}$

Respecto de este último caso, en la Orden Ministerial de 30 de abril de $1977,{ }^{55}$ se establece expresamente que no se genera el derecho a la prestación de incapacidad temporal, cuando la baja se produce durante la situación de huelga, siempre que la causa sea una "enfermedad común 0 accidente no laboral". Por consiguiente "a sensu contrario" hay que entender que sí se genera el derecho, cuando la causa es un accidente de trabajo o una enfermedad profesional, no obstante lo cual y dado el efecto suspensivo de la huelga en la legislación española, debe tenerse presente que el artículo $115.1^{56}$ de la Ley General de Seguridad Social exige igualmente para calificar un accidente como de trabajo, que exista una relación causal entre la lesión y el trabajo.

Con respecto al Alta Especial en que se encuentran para efectos de la Seguridad Social, los trabajadores que ejercen el derecho de huelga en España, se ha señalado doctrinariamente que su fundamentación político-legislativa "trata de evitar que el huelguista vea menoscabada su cobertura, evitando asi que la Seguridad Social sea un obstáculo del libre ejercicio del derecho fundamental”, puesto que la huelga tiene tal entidad que "quien usa su derecho no puede recibir consecuencia negativa alguna (más allá de la propia derivada de la sinalagmaticidad de la relación laboral)." ${ }^{57}$

\section{CONCLUSIONES}

En base a lo expuesto en la presente investigación, se observa como un aspecto deficitario de nuestra legislación de seguridad social, incluyendo la normativa sobre riesgos del trabajo o, al menos de la interpretación administrativa que de ella se efectúa, el que se otorgue una cobertura limitada a los trabajadores en huelga o, en el caso de la Ley $\mathrm{N}^{\circ} 16.744$, que se efectúe una distinción entre la cobertura que se otorga a los dirigentes sindicales por los accidentes que sufran a causa o con ocasión de su cometido gremial, negando la misma a los socios o afiliados a las organizaciones sindicales que sufren accidente durante el ejercicio de estas actividades sindicales, particularmente en situaciones de huelga. En este sentido, conviene traer a colación la reflexión de la jurisprudencia constitucional española, al sostener que "se hace indispensable la necesidad de aplicar de forma inflexible el principio de no discriminación por el ejercicio del derecho fundamental. ${ }^{\prime 58}$ A lo anterior, debe agregarse que, tal como lo vimos, el Comité de Libertad

\footnotetext{
${ }^{53}$ En Sala Franco y Albiol (2003) p. 456.

54 Artículo 2, Orden Ministerial de 30 de abril de 1977 que desarrolla algunos aspectos del Real Decreto Ley

17/1977 de 4 de marzo sobre relaciones de trabajo (derecho de huelga), en materia de seguridad social.

55 Ibídem.

56 "Se entiende por accidente de trabajo toda lesión corporal que el trabajador sufra con ocasión o por consecuencia del trabajo que ejecute por cuenta ajena.".

${ }^{57}$ En Monereo (2013) p. 368.

58 Sentencia del Tribunal Constitucional (STC), del 14 de junio de 1993, citada en Sala Franco y Albiol (2003) p.
} 
Sindical califica como de la mayor gravedad, los actos de discriminación que afecten a los trabajadores por el ejercicio de este derecho fundamental.

Por tanto, no se encuentra desde nuestra perspectiva, una razonabilidad suficiente en la desprotección generalizada de los trabajadores que ejercen su derecho fundamental a la huelga en nuestro medio, lo que puede transformarse en una "medida discriminatoria" de los trabajadores sindicalizados, porque aumenta las cargas del trabajador en el ejercicio de la más específica herramienta de presión laboral, como lo es la huelga, al diferenciarlos injustificadamente del resto de trabajadores no comprometidos en este proceso, quienes en situaciones similares de causalidad con el trabajo, si tienen la cobertura de la Ley $\mathrm{N}^{\circ} 16.744$ por los accidentes laborales que sufren en las mismas situaciones.

Tampoco se observa consistencia de la Jurisprudencia de la Superintendencia de Seguridad Social cuando, por una parte, otorga amplia protección a los dirigentes de Asociaciones de Funcionarios y al delegado del personal que, como anotáramos antes, implica un criterio "pro hominem" para interpretar la expresión dirigentes de instituciones sindicales del artículo $5^{\circ}$ inciso $3^{\circ}$ de la Ley $\mathrm{N}^{\circ} 16.744$, mientras que por otro lado, deja en la desprotección a los trabajadores en huelga, porque si se sigue la norma con criterios formalistas, las huelgas del sector público están prohibidas, inclusive, en la Constitución y en los respectivos Estatutos Administrativos y, por ende, podría concluirse el absurdo que a los dirigentes sindicales del sector público, les estaría prohibido realizar o participar en ese tipo de actividades sindicales, lo que conduciría al insólito de afirmar que tampoco tendrían protección contra los accidentes del trabajo que sufran en estas actividades "ilegales". 59

Ahora bien, resulta necesario observar que el propio artículo 377 del Código del Trabajo, autoriza al trabajador en huelga para que efectúe trabajos fuera de la empresa y que, por tanto, que no participe activamente en la huelga, condicionándosele, no obstante, la cobertura del seguro de accidentes del trabajo por esas otras funciones, siempre que cotice para la Ley $\mathrm{N}^{\circ}$ 16.744. Parece ser que, según los casos, los efectos suspensivos del artículo 377 pueden implicar un circulo poco virtuoso, pues la falta de ingresos laborales durante la huelga, generaría en algunos trabajadores la necesidad de procurarse ingresos alternativos, lo que debilita el carácter colectivo del ejercicio del derecho a huelga y, dado el carácter temporal de estas funciones fuera de la empresa, probablemente no estará sujeta a cotizaciones, generándose así un empleo precario y desprotegido.

La huelga, entendida como un derecho fundamental, debería ser considerada como una de las dimensiones colectivas del propio trabajo y vinculadas íntimamente a su defensa y protección, por lo que si ello fuera efectivo, debiera ser cubierta en materia de accidentes del trabajo, como una manifestación más de la protección a la libertad sindical, a lo menos, respecto de toda lesión que el trabajador sufra con ocasión del trabajo, sin necesidad de efectuar cambios normativos, pero dejando de lado interpretaciones que restrinjan injustificadamente el pleno ejercicio de este derecho fundamental.

452.

59 En este sentido, en sentencia de 30.09.2015, rol N 66-551 sobre Recurso de Protección, la I. Corte de Apelaciones de Santiago resolvió que el artículo 35 y siguientes del Estatuto Docente, establece las causas que justifican la no asistencia a sus labores, dentro de los cuales, no se contempla "asistir o participar en un paro de actividades”. En el mismo sentido Dictamen N 4.981, 04.02. 2004, de la Contraloría General de la República. 


\section{BIBLIOGRAFÍA}

BARBAgelata, Héctor-Hugo (2009): El Particularismo del Derecho del Trabajo y los Derechos Humanos Laborales. (Montevideo, Editorial Fondo de Cultura Universitaria, segunda edición).

Gómez Martínez, José Luis (2015): "Discurso de angostura: Discurso pronunciado por el libertador ante el Congreso de Angostura el 15 de febrero de 1819, día de su instalación” Disponible en http://www.ensayistas.org/antologia/XIXA/bolivar/bolivar2.htm.

ERMIDA URIARTE, OsCAR (2012 a): Sindicatos en Libertad Sindical. (Montevideo, Editorial Fondo de Cultura Universitaria, cuarta edición).

ERMIDA URIARTE, Oscar (2012 b): Apuntes sobre La Huelga. (Montevideo, Editorial Fondo de Cultura Universitaria, tercera edición).

GAETE BERRÍOS, AlFredo (1953): Derecho Colectivo del Trabajo. (Santiago, Editorial Jurídica de Chile).

GAMONAL CONTRERAS, SERgio (2011): Derecho Colectivo del Trabajo. (Santiago, Editorial Legal Publishing, segunda edición).

HUMERES MAGNAN, HÉCTOR (1957): en Cartilla N 11 "La Huelga", (Santiago, Editorial Jurídica de Chile).

LANATA FUENZALIDA, GABriela (2012): Sindicatos y Negociación Colectiva. (Santiago, Editorial Legal Publishing).

MARTÍN, VALVERDE, ANTONIO; RODRÍGUEZ-SAÑUDO GUTIÉRREZ, FERMÍN Y GARCIA MURCIA, JOAQUíN (2013): Derecho del Trabajo. (Madrid, Editorial Tecnos, vigesimosegunda edición).

MONEREO PÉREZ, JosÉ LuIS (Coordinador) (2002): Derecho de Huelga y conflictos colectivos. Estudio crítico de la doctrina jurídica. (Granada, Editorial Comares).

ORGANIZACIÓN INTERNACIONAL DEL TRABAJO (2006): La Libertad Sindical, Recopilación de decisiones y principios del Comité de Libertad Sindical del Consejo de Administración de la OIT. (Ginebra, quinta edición).

PALOMEQUE LÓPEZ, Manuel Carlos; ALVAREZ DE LA ROSA, MANuel (2013): Derecho del Trabajo. (Madrid, Editorial Comares, vigesimoprimera edición).

ROJAS MIÑO, IRENE (2014): Derecho del Trabajo. Derecho Individual del Trabajo. (Santiago, Editorial Legal Publishing).

SALA FRANCO, TOMÁs y ALBIOL MONTESINOS, IgNACIO (2003): Manual de Derecho Sindical. (Valencia, Editorial Tirant Lo Blanch). 
SALA FRANCO, TOMÁs (Director) (2011): Relaciones Laborales. (Valencia, Editorial Tirant Lo Blanch, tercera edición).

SALINERO BERARDI, JORGE (2006): "Veinte años de afiliación sindical y negociación colectiva en Chile: Problemas y Desafíos” Disponible en: $<$ http://www.dt.gob.cl/documentacion/1612/articles-94126 recurso 1.pdf>

TAPIA GUERRERO, FrANCISCO, (2007): Sindicatos. (Santiago, Editorial LexisNexis, segunda edición).

TAPIA GUERRERO, FRANCISCO (2009): "El reconocimiento constitucional de la libertad sindical y el derecho de negociación colectiva", en Negociación colectiva en Chile: un derecho imprescindible, Dirección del Trabajo, Santiago.

THAYER ARTEAGA, William; NOVOA FUENZALIDA, Patricio (2012): Manual de Derecho del Trabajo, Tomo II. (Santiago, Editorial Jurídica de Chile, cuarta edición).

UGARTE CATALDO, JosÉ LuIs (2011): Tutela de Derechos Fundamentales del Trabajador. (Santiago, Editorial Legal Publishing, cuarta edición).

UGARTE CATALDO, JosÉ LUIS; CAAMAÑO ROJO, EDUARDO (2008): Negociación Colectiva y Libertad Sindical. Un enfoque crítico. (Santiago, Editorial Legal Publishing). 